\title{
Analysis of physical and mechanical properties of vacuum treated claydite-concrete
}

\author{
Alan Khubaev ${ }^{1, *}$, Tembot Bidov $^{1}$, and Alina Rybakova ${ }^{1}$ \\ ${ }^{1}$ Moscow State University of Civil Engineering, Yaroslavskoe shosse, 26, Moscow, 129337, Russia
}

\begin{abstract}
In this article the analysis of the impact of some physical and mechanical properties of vacuum treated claydite-concrete is presented. The work purpose is to describe in detail the results of the experimental and analytical studies of the claydite-concrete composition influence on the vacuum treatment intensity and amount of removed water. These results are obtained by solving the following problems: compressive strength investigation of the claydite-concrete samples; consideration of the phenomenon of "self-vacuuming treatment" of the porous aggregate as a factor, promoting claydite-concrete strength; consideration of such an aspect as "adhesion between clayditeconcrete and reinforcement", and the porosity learning as a factor of the quality assessing of the building products and structures. A scientific and technical hypothesis is formed, which assumes the possibility of the practical recommendation developing for vacuum treatment intensity of the claydite-concrete. As a result, this gives an opportunity to intensify the concrete hardening.
\end{abstract}

\section{Introduction}

The concrete production with specified properties is one of the most important tasks in concrete technology. It is especially difficult because of the necessary consideration of the factor variety, which characterize the claydite-concrete component quality when selecting the vacuum treated claydite-concrete compositions.

One of the main advantages of the vacuum treatment technology of the freshly laid claydite-concrete with time-separated process of the water removal and vacuum seal, along with the intensification of the process of the concrete hardening, is to obtain a material with increased physical and mechanical properties. The physical and mechanical property improvement of the vacuum treated claydite-concrete with time-separated processes of water removal and vacuum seal is due to the fact that the structure density is increasing and more complete cement hydration is ensured.

\footnotetext{
* Corresponding author : alan_khubaev@mail.ru
} 


\section{Materials and methods}

To fully assess the technological factor influence on the strength properties of the clayditeconcrete we previously conducted laboratory studies. Vacuum-treated samples were stored in a normal hardening chamber and tested for compression after 1, 3, 7, 14 and 28 days. Thus, the values of compressive strength depending on the mode of, temperature and composition $[1,2]$ were determined using the static processing of experiment results. After processing of the received results of the laboratory experiments the regression equation was compiled and the model most fully describing the function under study was selected $[5,6]$. The substitution of the values of the investigated factor, with the stabilization of the others at the same level, makes it possible to obtain mathematical dependences of each factor influence at various levels on the resultant value of the claydite-concrete strength [7]. Based on the obtained data analysis, it was found that the best results are achieved by the vacuum treatment of the claydite-concrete heated to $60^{\circ} \mathrm{C}$ at a depression of $0.075 \mathrm{MPa}$, in which large sand was used $(\mathrm{Mk}=3.1)$. A special role plays the volume concentration of the porous aggregate (Figure 1). It was found that the greatest compressive strength at 28-day age is reached with a minimum value of $0,3 \mathrm{~m} 3 / \mathrm{m} 3$. At the same time, the use of concrete with a volume concentration of the claydite gravel of $0.5 \mathrm{~m} 3 / \mathrm{m} 3$, contributes to a significant increase in strength in the first three days. These results can be explained by the fact that at the initial stage of the hardening an increased concentration of porous aggregate, especially the phenomenon of "self-vacuuming treatment" of the claydite-concrete has a great influence on the strength buildup.

Freshly prepared concrete, consisting of claydite gravel, represents a capillar and porous solid made of a porous aggregate, sand and cement paste. After the water addition to a concrete mix in the contact of "porous aggregate" with "cement grout" complex physical and chemical processes take place, the nature of which determines the adhesive properties between the aggregate and cement and, consequently, the properties of expanded clay concrete. Possessing water-absorbing ability of the claydite gravel grain immobilize the part of the mixing water from the cement paste according to the principle of the vacuum pumps, as a result of which a phenomenon called by prof. Simonov M.Z." selfvacuuming treatment" of the porous aggregate in the lightweight concrete mix. During the subsequent hardening claydite-concrete moisture, accumulated by aggregate grains, is again given to the cement stone, without causing the expansion of cement grains and the appearance of new pores in the cement stone at the same time, which is beneficial pleasantly affects on the formation of a strong concrete structure. Comparing the "selfvacuuming treatment" of the porous aggregate in lightweight concrete to the concrete with dense aggregates, the harmful effects of sedimentation processes are less affected, as a result of this processes on the surface of the aggregate water layers are usually formed, which reduce the concrete strength. In addition, the developed surface and the ability to accumulate water from the cement paste provide the claydite gravel with good adhesion to cement stone. The state of the contact zone determines new physical and mechanical properties of concrete. Study of the destruction nature of the claydite-concrete samples showed that the gap occurs, as a rule, along the body of the aggregate.

In this case, a strongly marked zone of the cement paste penetration into the surface layer of the aggregate is observed. The thickness of the diffusion layer depends on the phenomenon development of the claydite gravel "self-vacuuming treatment", which takes part for a long time under the different conditions and with varying intensity. The thickness also depends on the size and aggregate nature, the method and duration of the treatment of the freshly prepared claydite-concrete and number of the other technological factors. 
a)

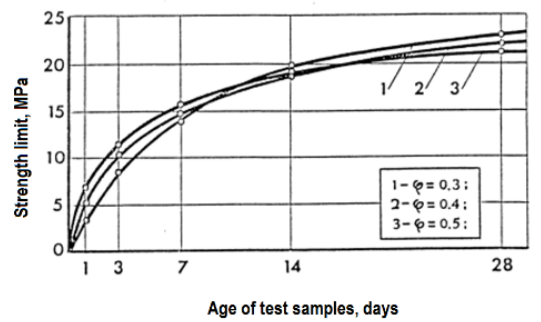

b)

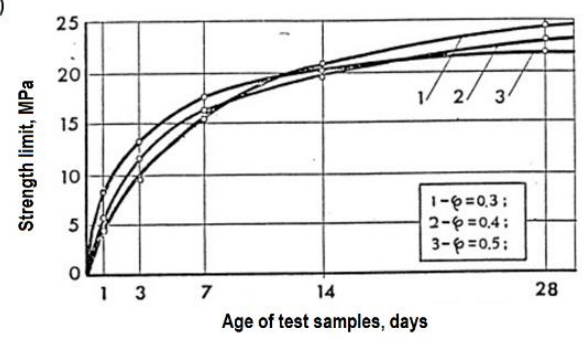

c)

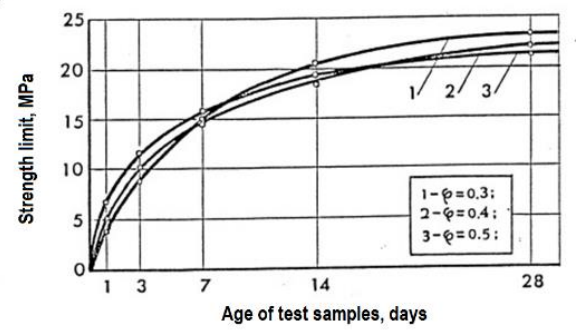

Fig. 1. Kinetics of the claydite-concrete strength under "self-vacuuming treatment" at a pressure of $0.075 \mathrm{MPa}$.

a) at the temperature of freshly prepared concrete $-40^{\circ} \mathrm{C}$; b) the same, $60^{\circ} \mathrm{C}$; c) the same, $80^{\circ} \mathrm{C}$

The investigations of the contact zone microstructure of the claydite gravel and cement stone by the help of an electron microscope (with 120 -fold magnification) make it possible to reveal that the largest "hardening zone" is achieved by vacuum treating of the freshly prepared claydite-concrete heated to $55-65^{\circ} \mathrm{C}$ at a vacuum of $0.075-0.0,09 \mathrm{MPa}$; and this zone is 3.2-4.7 $\mathrm{mm}$ (for claydite-concrete, not subjected to vacuum action, the thickness of the diffusion layer is I, 2-2.3 mm). These results become natural if we consider the physical processes taking place in the processed claydite-concrete. The air and the steam-air mixture, which are in the pores of the porous aggregate, during the vacuum treatment process become "sparse" [3]. After the end of the vacuum treatment, this mixture, as well as a part of the cooling down and immobilized water, decreases in volume, it leads to a certain imbalance of pressures in the aggregate pores and in the cement paste. Due to the pressure difference formation, the cement paste penetrates into the pores of the claydite gravel. In this case the greater the pressure difference, the greater the thickness of the diffusion layer is.

The main feature of reinforced concrete as a structural material is a collaboration of th reinforcement and concrete, provided by the coupling between them. Due to the contact on the contact surface between concrete and reinforcement, the slip does not occur in the concrete.

According to established views, the adhesion strength between reinforcement and concrete is provided by the following factors: engaging of the protrusions in the concrete on the surface of the profiled reinforcement; frictional forces developing on the contact of the reinforcement and concrete due to its shrinkage; adhesion or "gluing" of the surface of the reinforcement and concrete, which is due to the adhesive capacity of the cement gel.

In the question, of which of these factors plays a decisive role in the overall resistance to the shift, there are disagreements. Most researchers in the field of the reinforced concrete believe that the bond strength due to the gluing is small and amounts to only about $25 \%$ of the total shift resistance. Other researchers, on the contrary, argue that it is not shrinkage, but that pure surface gluing has a predominant significance in the overall shear resistance. 


\section{Results}

On the analysis basis of the investigation of K.V. Mikhailov and based on the number of other authors, it follows that the adhesion of the reinforcement and claydite-concrete under vacuum treatment should increase due to an increase in the resistance of mechanical engagement and friction from shrinkage. To study the influence of the technological parameters on the adhesion of the reinforcement and claydite-concrete, a number of laboratory experiments was carried out. The experiments to determine the adhesion value were carried out by pushing rods of steel St. 3, $16 \mathrm{~mm}$ in diameter, concreted into the samples measuring $15 \times 15 \times 15 \mathrm{~cm}$. The extrusion test was carried out after 28 days storage of the samples in a normal hardening chamber. The adhesion value is defined as the quotient of the force in the rod divided by the surface of the seal:

$$
\tau_{\mathrm{c}}=\frac{N}{l_{3} \times n}
$$

Where $\tau_{\mathrm{c}}$ - clutch tension;

$N$ - force in rod; $l_{3}$ - length of the rod closing; $n$ - perimeter of the rod section.

The adhesion tension was determined for claydite-concrete vacuum treated and untreated. The results of the studies are given in the Table 1.

Table 1. Effect of claydite-concrete composition and degree of rarefaction on adhesion of reinforcement and concrete

\begin{tabular}{|c|c|c|c|c|c|c|}
\hline \multirow{3}{*}{$\begin{array}{l}\text { Sand } \\
\text { size } \\
\text { module }\end{array}$} & \multirow{3}{*}{$\begin{array}{c}\text { Cement content, } \\
\mathrm{kg} / \mathrm{m} 3\end{array}$} & \multirow{3}{*}{$\begin{array}{c}\text { Volumetric } \\
\text { concentration } \\
\text { of claydite } \\
\text { gravel, } \\
\mathrm{m}^{3} / \mathrm{m}^{3}\end{array}$} & \multicolumn{4}{|c|}{$\begin{array}{l}\text { Tension of adhesion of reinforcement } \\
\text { and claydite-concrete, } \mathrm{MPa}\end{array}$} \\
\hline & & & \multicolumn{3}{|c|}{$\begin{array}{c}\text { Under vacuum } \\
\text { treatment when negative } \\
\text { pressure }(\mathrm{MPa})\end{array}$} & \multirow[t]{2}{*}{$\begin{array}{l}\text { Untreated } \\
\text { by vacuum }\end{array}$} \\
\hline & & & 0.06 & 0.075 & 0.09 & \\
\hline 1 & 2 & 3 & 4 & 5 & 6 & 7 \\
\hline \multirow{9}{*}{2.3} & \multirow{3}{*}{320} & 0.3 & 1.2 & 1.6 & 1.3 & 0.8 \\
\hline & & 0.4 & 1.4 & 1.9 & 1.6 & 1.1 \\
\hline & & 0.5 & 1.6 & 2.4 & 1.9 & 1.2 \\
\hline & \multirow{3}{*}{344} & 0.3 & 1.3 & 2.0 & 1.6 & 0.9 \\
\hline & & 0.4 & 1.9 & 2.7. & 2.3 & 1.3 \\
\hline & & 0.5 & 2.6. & 3.2 . & 2.8 . & 1.7. \\
\hline & \multirow{3}{*}{368} & 0.3 & 1.5 & 1.8 & 1.7. & 1.1 \\
\hline & & 0.4 & 1.8 & 2.3 & 2.0 & 1.3 \\
\hline & & 0.5 & 2.3 & 2.6 . & 2.4 & 1.8 \\
\hline \multirow{9}{*}{3.1} & \multirow{3}{*}{320} & 0.3 & 1.5 & 2.4 & 1.6 & 1.2 \\
\hline & & 0.4 & 1.9 & 2.4 & 2.0 & 1.6 \\
\hline & & 0.5 & 2.1 & 2.8 . & 2.4 & 1.7. \\
\hline & \multirow{3}{*}{344} & 0.3 & 1.7. & 2.4 & 2.1 & 1.3 \\
\hline & & 0.4 & 2.4 & 3.1 & 2.7 & 1.7 \\
\hline & & 0.5 & 3.1 & 3.7 & 3.4 . & 2.2 \\
\hline & \multirow{3}{*}{368} & 0.3 & 1.9 & 1.9 & 2.1 & 1.5 \\
\hline & & 0.4 & 2.2 & 2.6. & 2.4 & 1.7. \\
\hline & & 0.5 & 2.7 . & 3.1 & 2.9 & 2.3 \\
\hline
\end{tabular}


On the basis of the obtained results, it follows that the adhesion tension of the reinforcement and claydite-concrete treated by the vacuum exceed these values by $1.5-2$ times for claydite-concrete aggregates not subjected to vacuum action. Moreover, the best results were achieved for concretes of composition: $\mathrm{C}=344 \mathrm{~kg} / \mathrm{m}, \varphi=0.5 \mathrm{~m} / \mathrm{m}$, with sand content of $\mathrm{Mk}=3.1$, which were treated at a vacuum of $0.075 \mathrm{MPa}$. Obtaining increased adhesion tension of the claydite-concrete under vacuum reatmen is a very important factor for monolithic construction in the areas with increased seismic activity.

The material has a great importance when assessing the quality of the construction products and structures. This is due to the fact that such important properties of concrete as strength, water absorption, permeability, thermal conductivity, frost-resistance, etc. are associated with it. Obviously, to obtain claydite-concrete with increased strength characteristics, it is necessary to reduce the cement stone porosity. At the same time, vacuum treatment of freshly prepared claydite-concrete inevitably leads to the formation of directed pores and capillaries, along which the removed liquid and the vapor-air mixture move. However, significant static pressures transmitted to the treated concrete by the suction device (during the vacuum-pressing process) destroy the structure of the material formed at the stage of the passive vacuum treatment. To confirm this, the laboratory research program provided the experiments to determine the influence of the rarefaction degree on the formation of the processed claydite-concrete structure. The total pore volume, the volume of the open capillary and non-capillary pores and the volume of conditionally closed pores of claydite-concrete treated by the vacuum at the rarefaction of 0.06, 0.075 and 0.09 $\mathrm{MPa}$ were determined [2].

The investigations were carried out in accordance with GOST 12730.4-78 "Concretes: Methods to determine porosity parameters". Analysis of the research results showed that when claydite-concrete of the same composition treated by the vacuum, the lowest porosity of the cement stone is achieved by vacuum treatment at a pressure of 0.075 $\mathrm{MPa}$. Moreover, the best results were obtained by treating mixtures heated to a temperature of $60^{\circ} \mathrm{C}$ (Table 2$)$.

Table 2. Average value of claydite-concrete porosity

\begin{tabular}{|c|c|c|c|c|c|}
\hline \multirow[t]{2}{*}{ Name of indicators } & \multirow{2}{*}{$\begin{array}{c}\text { Processed } \\
\text { concrete } \\
\text { temperature, }{ }^{\circ} \mathrm{C}\end{array}$} & \multicolumn{3}{|c|}{$\begin{array}{l}\text { Vacuum treated at pressure } \\
(\mathrm{MPa}) \text { : }\end{array}$} & \multirow{2}{*}{$\begin{array}{l}\text { Untreated } \\
\text { by } \\
\text { vacuum }\end{array}$} \\
\hline & & 0.06 & 0.075 & 0.09 & \\
\hline \multirow{3}{*}{$\begin{array}{c}\text { Total pore volume, } \\
\%\end{array}$} & 40 & 11.4 & 8.1 & 11.9 & 22.7 \\
\hline & 60 & 10.6 & 6.8 & 11.2 & 21.0 \\
\hline & 80 & 11.0 & 10.9 & 11.7 & 20.6 \\
\hline \multirow{3}{*}{$\begin{array}{c}\text { Including volume } \\
\text { of open } \\
\text { capillary pores, \% }\end{array}$} & 40 & 4.5 & 3.0 & 5.0 & 13.1 \\
\hline & 60 & 3.9 & 2.7 . & 4.5 & 11.9 \\
\hline & 80 & 4.3 & 4.7 & 4.6 & 10.6 \\
\hline \multirow{3}{*}{$\begin{array}{c}\text { The volume of } \\
\text { open non- } \\
\text { capillary pores, \% }\end{array}$} & 40 & 4.8 & 2.6. & 3.8 & 8.1 \\
\hline & 60 & 3.9 & 1.2 & 2.9 & 8.3 \\
\hline & 80 & 4.3 & 2.4 & 3.5 & 7.9 \\
\hline \multirow{3}{*}{$\begin{array}{l}\text { The volume of } \\
\text { conditionally } \\
\text { closed pores, } \%\end{array}$} & 40 & 2.1 & 2.5 & 3.1 & 1.5 \\
\hline & 60 & 2.8 . & 3.9 & 3.8 & 1.7. \\
\hline & 80 & 2.4 & 3.8 & 3.6 . & 2.1 \\
\hline
\end{tabular}

It is established that the formation of the material structure is interrelated with the deformative processes occurring during the compression compacting of claydite-concrete, as well as with the water removal process. The more fully and uniformly the compressive pressure is distributed over the entire thickness of the treated mass [3] and the more water is 
pressed [3], the less porous becomes concrete (Figure 2). These regularities explain the fact that the vacuum treatment of claydite-concrete aggregates at the pressure 0.06 and 0.09 $\mathrm{MPa}$, leads to providing the material with a higher porosity, as well as a nonuniform distribution over the entire thickness of the treating layer (Figure 2).
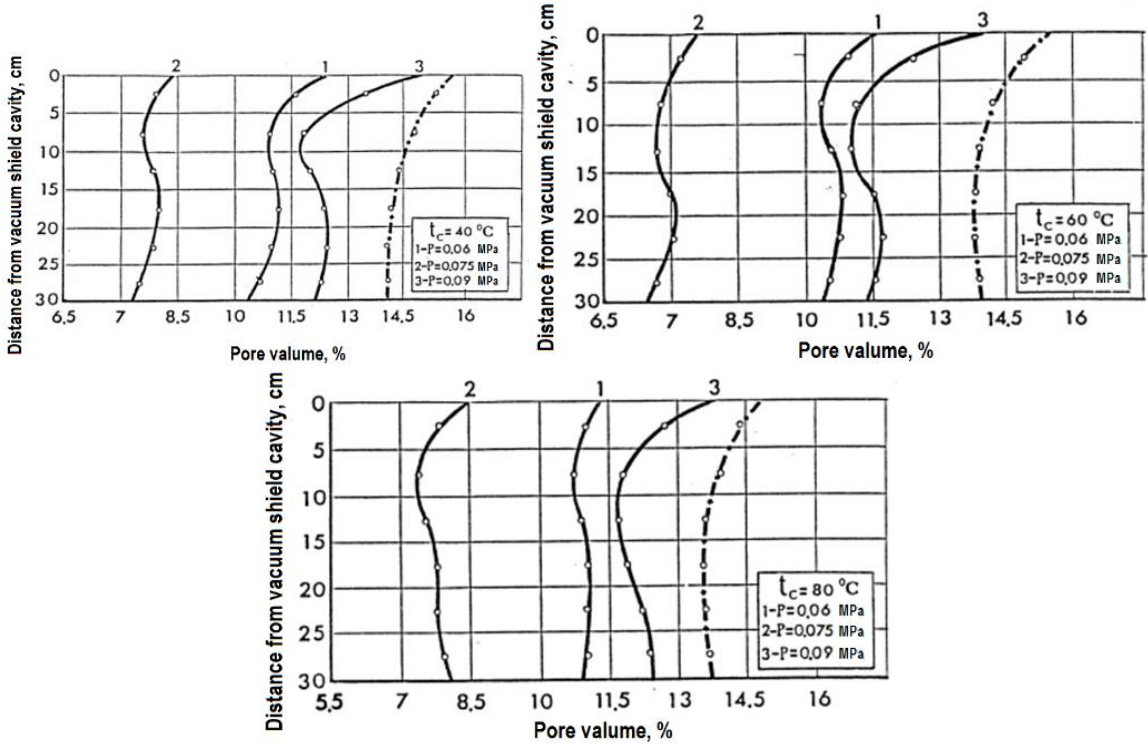

Fig. 2. Distribution of total pore volume in claydite-concrete untreated by vacuum(- - -) and vacuum treated (-) .

1 - at a pressure of $0.06 \mathrm{MPa} ; 2$ - the same, $0.075 \mathrm{MPa} ; 3$ - the same, $0.09 \mathrm{MPa}$

Based on the analysis of the obtained data, it follows that as a result of the vacuum treatment of the claydite-concrete, a significant reduction in the porosity indices is achieved as compared to the claydite-concrete aggregate untreated by the vacuum. This leads to an increase in strength, frost-resistance, durability of the material, extinction of its water absorption .

\section{Conclusion}

Summing up, we will emphasize the following conclusions:

1.Quantitative and qualitative analysis of the solid components removed from the claydite-concrete during vacuum treatment showed that the amount of solid particles whose diameter is in the range $8-26$ microns, is $0.15-0.23 \%$ of the total urging fluid.

2.Vacuum treatment of the freshly prepared claydite-concrete increases its physical and mechanical characteristics in comparison with the concrete untreated by the vacuum. The compressive strength is increased by $20-23 \%$, the concretion of the concrete and reinforcement is $1.3-1.9$ times, the concrete porosity is reduced by $2-3$ times.

\section{References}

1. A.A.Lapidus, V.D.Kopylov,A.E.Stepanov,A.O.Khubaev, Nauchnoe obozrenie, 14, 233-238 (2016)

2. A. A. Lapidus, V. D. Kopylov, A. E. Stepanov, A. O. Khubaev, Nauchnoe obozrenie, 14, 233-238 (2016) 
3. A. O. Khubaev, Perspektivi nauki, 11 (98), 43-47 (2017)

4. A. Lapidus, T. Bidov, A. Khubaev, MATEC web of conferences, 117, 00094 (2017)

5. A. A. Lapidus, A. O. Khubaev, Nauka I biznes: puti razvitija, 11 (77), 3-11 (2017)

6. A. A. Lapidus, Vestnik MGSU, 12, 114-121 (2016)

7. R. S. Fatuullaev, Nauka I biznes: puti razvitija, 9 (75), 34-40 (2017)

8. I. Abramov, A. Stepanov, I. F. Ibrahim, MATEC web of conferences, 117, 00001 (2017) 